\title{
Grandfamilies and the Opioid Epidemic: A Systemic Perspective and Future Priorities
}

\author{
Megan L. Dolbin-MacNab ${ }^{1,3}$ [D $\cdot$ Lyn M. O'Connell ${ }^{2}$
}

Accepted: 2 January 2021 / Published online: 25 January 2021

(c) The Author(s), under exclusive licence to Springer Science+Business Media, LLC part of Springer Nature 2021

\begin{abstract}
As a result of the devastating impact of the opioid epidemic, increased numbers of children are being raised by their grandparents in what are known as grandfamilies. Despite these children and their families experiencing difficult environmental circumstances, numerous adverse life events, and challenging family dynamics, empirical examinations of the opioid epidemic, as it relates to grandfamilies, remain limited. The purpose of this review is to advance the understanding of how grandfamilies have been impacted by the opioid epidemic by using a systemic perspective to highlight themes and major conclusions within the existing conceptual and empirical literature. The review reveals five systemically informed themes including the assumption of caregiving responsibilities, grandparent stress and well-being, caring for vulnerable grandchildren, navigating relationships with parents, and contextual stressors of societal stigma and barriers to service. To extend this work, systemically informed recommendations for clinical intervention and future priorities for research and policy are discussed.
\end{abstract}

Keywords Grandparents raising grandchildren · Kinship care · Grandparents · Opioid · Intervention · Policy

The opioid epidemic, which was declared a public health emergency by the United States Department of Health and Human Services (2017), has had significant negative consequences for individuals, children, and families. Approximately 2 million US individuals have an opioid use disorder (OUD; SAMHSA 2019), with opioids contributing to almost $70 \%$ of drug overdose deaths (Centers for Disease Control and Prevention, CDC 2019; Wilson et al. 2020). Opioid overdoses continue to be a leading cause of death in the United States, annually claiming the lives of approximately 15 individuals per 100,000 (CDC 2019). Many of the people who misuse opioids or die from opioid overdoses are parents (Feder et al. 2018). As a result, every $15 \mathrm{~min}$, a US infant is born with opioid exposure (Honein et al. 2019)

Megan L. Dolbin-MacNab

mdolbinm@vt.edu

1 Department of Human Development and Family Science, Virginia Tech, Blacksburg, VA, USA

2 Joan C. Edwards School of Medicine, Marshall University, Huntington, WV, USA

3 Family Therapy Center of Virginia Tech (0515), 840 University City Boulevard, Suite 1, Blacksburg, VA 24060, USA and estimates reveal that the number of children living with a parent with OUD increased 30\% between 2002 and 2017, and $200 \%$ for children living with an adult who misuses heroin (Bullinger and Wing 2019). Children impacted by parental opioid misuse are at increased risk for maltreatment, removal from their parents, and temporary placement with alternative caregivers (Radel et al. 2018). Child welfare systems may be overwhelmed as they attempt to find safe placements for these children.

When parents are unable to care for their children, grandparents have a long history of assuming caregiving responsibilities (Hayslip et al. 2017). In the United States, there are approximately 7.9 million children living with grandparents or other relatives, with 2.65 million of those children (or $4 \%$ of all US children) living in "skipped generation" homes with no biological parents present (Annie E. Casey Foundation Kids Count Data Center 2020). While some of the approximately 2.5 million grandparents raising grandchildren (US Census Bureau 2020a) are doing so formally through the child welfare or foster care system, the majority of grandparents are raising their grandchildren informally (Generations United 2018). Calculations by Generations United (2018), using data from the Community Survey and the Adoption and Foster Care Analysis and Reporting 
System (AFCARS), reveal that only $5 \%$ of children residing in skipped generation households are part of the foster care system. Whether the care arrangement is formal or informal, by providing their grandchildren with stable and permanent homes, and by maintaining their connections to their families, communities, and culture, grandparents are critical safety nets for their families (Generations United 2018). Additionally, by keeping their grandchildren out of the foster care system, Generations United (2018) used federal foster care maintenance payment data to estimate that grandparents save taxpayers approximately $\$ 4$ billion per year.

Grandfamilies, or families in which grandparents are raising their grandchildren, are demographically heterogenous. That said, compared to grandparents not residing with their grandchildren, custodial grandparents are more likely to be female, single, under the age of 60, and less educated (Ellis and Simmons 2014). Although the majority of custodial grandparents participate in the workforce, approximately $19 \%$ are still living in poverty (US Census Bureau 2020a). With regard to race and Hispanic origin, American Indian/ Alaskan Native, Hispanic, and Black grandfamilies are disproportionately represented, though numbers of White, Non-Hispanic grandfamilies are increasing (Ellis and Simmons 2014; Livingston and Parker 2010). In noting these demographic characteristics, it should be emphasized that the intersectional nature of race, gender, class, and age likely places some grandfamilies at greater risk for marginalization and negative outcomes than others (Dolbin-MacNab and Few-Demo 2018).

Within the United States, both macro- and microsystemic factors influence grandfamily formation. Macrosystemic factors such as economic instability and state and federal child welfare policies mandating the placement of children with relatives contribute to the creation of grandfamilies (Beltran 2018; Livingston and Parker 2010). Additionally, polices that emphasize family (versus government) responsibility for the care of its members may push grandparents into custodial roles (Baker et al. 2008). Beyond these influences, cultural traditions of multigenerational households and grandmother involvement in childcare underlie many grandfamilies (Goodman and Silverstein 2002). Even dominant cultural expectations of women as caregivers are relevant to the formation of grandfamilies, as are racial, gender, and class disparities related to education, employment, and incarceration-all of which can impede parents' ability to provide for their children (Bozalek and Hooyman 2012; Dolbin-MacNab and Few-Demo 2018).

Despite the importance of macrosystemic factors to the formation of grandfamilies, microsystemic factors, namely difficulties that render parents unable to care for their children, are the most commonly referenced reasons why grandparents raise their grandchildren. These difficulties include parental abuse and neglect, substance misuse, physical and mental illness, death, incarceration, military deployment, divorce, abandonment, and adolescent pregnancy (Hayslip et al. 2017). Although these contributing factors are intertwined, parental substance misuse is frequently cited as the most common reason why grandparents raise their grandchildren (e.g., Generations United 2018). In fact, the initial scholarship on grandfamilies primarily considered grandmothers' needs within the context of the crack cocaine epidemic of the 1980s and 1990s (e.g., Burton 1992; Minkler and Roe 1993; Minkler et al. 1992; Roe et al. 1994). Today, the devastating impact of the opioid epidemic has thrust grandfamilies back into the public spotlight, perhaps most evidenced by a 2017 US Senate Special Committee on Aging hearing entitled, "Grandparents to the Rescue: Raising Grandchildren in the Opioid Crisis and Beyond" and the subsequent passage of the Supporting Grandparents Raising Grandchildren Act (S.1091) in 2018. This legislation resulted in the formation of the Federal Advisory Council to Support Grandparents Raising Grandchildren (Supporting Grandparents Raising Grandchildren Act 2018; United States Senate Special Committee on Aging 2017).

Although more data are needed, emerging evidence suggests that the opioid epidemic has contributed to increased numbers of grandfamilies. In a survey of programs assisting grandparents raising grandchildren, program leaders indicated that nearly all of their participant grandfamilies were impacted by parental substance misuse and $70 \%$ specifically referenced opioids, namely heroin (Generations United 2018). More broadly, using data from the CDC and US Census Bureau, Anderson (2019) found that, after controlling for a number of demographic characteristics (e.g., race, poverty, total population, metropolitan status), the states with the highest percentages of grandparents raising grandchildren were also the states with the highest opioid prescribing rates. Within the child welfare system, parental substance misuse has resulted in increased numbers of children entering foster care, as well as increased numbers of children being placed with relatives in kinship care (Sepulveda and Williams 2019; Williams and Sepulveda 2019). Between 2007 and 2017, the percentage of children in kinship care increased from 26 to $33 \%$ (Williams and Sepulveda 2019). And, for approximately $36 \%$ of the children in foster care, parental drug misuse was a main reason for the out of home placement (Sepulveda and Williams 2019).

Despite the likelihood that the opioid epidemic has resulted in increased numbers of grandfamilies and renewed public interest in this population, empirical examinations of grandfamilies within the context of the opioid epidemic remain limited. Additionally, discussions of parental substance misuse and grandfamilies tend to narrowly focus on grandparents' experiences and fail to consider the interdependent individual, familial, community, and societal forces that are relevant to understanding their experiences. 
Therefore, the purpose of this review is to advance the understanding of how grandfamilies have been impacted by the opioid epidemic by using a systemic perspective (Minuchin 1985) to highlight themes within the existing conceptual and empirical literature. To extend this work, we offer systemically informed recommendations for clinical intervention and outline future priorities for research and policy. Given the significant numbers of grandfamilies impacted by the opioid epidemic, pursuit of these priority areas can help preserve family connections and benefit the health and well-being of custodial grandparents, their grandchildren, and the grandchildren's biological parents.

\section{A Systemic Perspective on the Opioid Epidemic}

Opioids are a highly addictive class of drugs that includes prescribed pain killers such as oxycodone, hydrocodone, codeine, and morphine, as well as synthetic opioids such as fentanyl and carfentanil, and the illegal drug heroin. The first wave of the opioid epidemic, from 1999 to 2010, arose from increased prescription opioid overdose deaths, with a second wave from 2010 to 2013 that was due to increases in overdose deaths due to heroin (CDC 2019). Today, overdose deaths reflect accelerated use of synthetic opioids, which represent two-thirds of all opioid overdose deaths (CDC 2019). Although opioid prescription rates have declined in recent years, deaths from heroin and synthetic opioid overdoses remain high (CDC 2019; Jones et al. 2018).

Opioids carry a high risk of lethality and individuals who develop an addiction to opioids experience cravings for the $\operatorname{drug}(\mathrm{s})$, compulsive seeking of opioids, and continued use despite adverse consequences (National Institute on Drug Abuse, NIDA 2020). Diagnostically, OUD represents a chronic relapsing brain disease marked by opioid addiction that results in clinically significant impairment or distress (American Psychiatric Association, APA 2013; NIDA 2020). Associated symptoms include impaired or loss of control (i.e., unsuccessful efforts to control opioid use), social impairment (i.e., failure to fulfill role obligations, interpersonal problems associated with opioid use), risky use (i.e., taking larger amounts over time, use in hazardous situations), and pharmacological criteria (i.e., tolerance and withdrawal symptoms; APA 2013). Individuals with OUD experience a high potential for overdose, increased risk of suicidality, and cycling periods of use and abstinence (Davis et al. 2020). For these reasons, having OUD can make it extremely difficult for individuals to care for themselves, let alone their children.

Substance use disorders (SUD), like OUD, stem from numerous biological and environmental factors, as well as genetic and developmental influences (NIDA 2020). As such, understanding the opioid epidemic in the context of grandfamilies requires consideration of multiple intersecting factors such as individual characteristics, family/relational dynamics, and larger community contexts and societal forces. Theoretically, a systemic perspective (Minuchin 1985; Vincenzes et al. 2019) usefully captures this complexity. According to this perspective, individuals are interdependent and are best understood by considering the multiple contexts (e.g., families, communities, society) in which they are embedded, as well as the bidirectional interactions among those contexts (Minuchin 1985; Vicenzes et al. 2019). One of the most critical contexts to the overall health and functioning of individuals is the family. Families establish recursive patterns of interaction (e.g., feedback loops) that regulate the behavior of its members and maintain family stability (i.e., homeostatic tendencies) (Minuchin 1985). Unfortunately, when families are challenged or perturbed by a crisis, such as parental opioid misuse, or the demands of normative life transitions, existing interaction patterns can result in maladaptive or symptomatic behavior from any family member. In response, the family must reorganize and establish new interaction patterns - a process which is often chaotic until the family reestablishes homeostasis. Of further relevance to grandfamilies impacted by parental opioid misuse are the multiple, overlapping subsystems (e.g., grandparent-grandchild, grandparent-parent, parent-grandchild) operating within the larger grandfamily system. Subsystems have their own interaction patterns, functions, and boundaries with other subsystems in the family, with boundaries varying widely in terms of their clarity and rigidity (Minuchin 1985). Subsystems are also organized hierarchically, with certain subsystems having greater power and authority within the larger family system than others. Grandfamilies impacted by parental opioid misuse may experience difficulties with subsystem boundaries and hierarchies, and may find themselves engaging in maladaptive interaction patterns or symptomatic behavior, as they respond to the family crisis. Contextual stressors may further strain the functioning of the grandfamily system.

From a systemic perspective (Minuchin 1985), any discussion of grandfamilies in relation to the opioid epidemic must attend to the larger contexts in which these families are embedded. In fact, the very existence of grandfamilies and the unique challenges they experience are shaped by both societal and cultural contexts. Societally, the opioid epidemic has its roots in flawed research and misrepresentations of the addictive qualities of opioids and the resulting mass marking and misleading advertising of opioids by pharmaceutical companies, followed by increased prescribing of opioids, namely OxyContin, for pain management (Jones et al. 2018). These drugs were flooded into vulnerable communities, thereby setting off the opioid epidemic. Although rigorous research, 
re-education campaigns, regulatory oversight, and investigations have helped combat the opioid epidemic (Jones et al. 2018), opioid misuse and overdose deaths remain high and result in children requiring new caregiver or custody arrangements, thus explaining the increase in numbers of grandfamilies.

The opioid epidemic has impacted families across racial groups, geographic regions, and socioeconomic classes; however, some communities have been differentially impacted, often in ways that reflect historical marginalization and disparities. Frequently, these communities include significant numbers of grandfamilies. For instance, the opioid epidemic has predominately impacted white communities (Cicero et al. 2014; Om 2018). Nonetheless, the media attention and governmental prioritization of funding for research and treatment, and their overall stance of compassion, stands in contrast to the mass incarceration and criminalization of the crack cocaine epidemic, which predominately impacted the Black community (Om 2018). Similarly, the opioid epidemic has ravaged rural communities, particularly those found in Appalachia (Moody et al. 2017; Rigg et al. 2018). Rural communities tend to have limited prevention, treatment, and harm reduction programs and existing programs may be hard to access due to geographic distance (Generations United 2018; Moody et al. 2017; Rigg et al. 2018). In fact, in a study of 21 custodial grandparents from rural Appalachia, Hansen et al. (2020) found that grandparents reported feelings of anguish related to the lack of treatment services available to their adult children and to seeing their once vibrant communities eroded by the opioid epidemic.

Socioeconomically disadvantaged communities, common in rural areas, have also borne the burden of the opioid epidemic (Rigg et al. 2018). As a result of national and industry-specific workforce changes, many of these workingclass communities have experienced economic distress as a result of declining wages, job loss, and unemployment (Moody et al. 2017; Rigg et al. 2018; Shanahan et al. 2019). When combined with low education, youth outmigration, and injuries and chronic pain associated with the physically demanding jobs common in these communities (e.g., mining and farming), risk for opioid misuse increases (Moody et al. 2017; Rigg et al. 2018). As a result of economic distress, and the associated erosion of infrastructure and services, feelings of despair and hopelessness can become common (Rigg et al. 2018; Shanahan et al. 2019). It is hypothesized that these feelings permeate communities and result in feedback loops that further erode the community and its families. Specifically, feelings of despair and hopelessness can result in maladaptive attempts by individuals, families, and communities to adjust or adapt (Minuchin 1985; Rigg et al. 2018; Shanahan et al. 2019). Case and Deaton (2020) argue that these social forces have collectively contributed to increased rates of drug overdose deaths, in what are known as "deaths of despair."

Individuals who experience OUD are frequently stigmatized by their families. Instead of being treated as if they have a chronic disease, they are perceived as being selfish, unable to cope with their lives, or as having failed morally (Engstrom 2008; Taylor et al. 2017). When an individual who has OUD is also pregnant or already a parent, the stigma is intensified, as they are frequently viewed as bad parents who are harming their children (Taylor et al. 2017). This stigma can even extend to the children of parents with OUD or SUD, as evidenced by previous references to the lost generation of "crack babies" (Roe et al. 1996, p. 1073). Systemically, families may express their feelings of stigma toward the family member with OUD, while attempting to maintain homeostasis in the face of crisis, in a variety of ways ranging from creating rigid boundaries and cutting off from the individual to loosening boundaries and becoming overinvolved in the individual's life.

Individuals with OUD experience similar stigma within their larger communities; stigma directed toward individuals who misuse substances and their families is evident in both intervention and policy arenas. For example, stigma has been associated with less evidence-based treatment policies and harsher punishments for drug use (McGinty et al. 2018). Similarly, stigma may amplify perceptions among child welfare professionals that removing children from their parents and placing them with alternative caregivers, such as grandparents, is the only course of action. Unfortunately, from a systemic perspective, these solutions may not account for existing enmeshed (i.e., loose, unclear boundaries) relationships between custodial grandparents and parents, often described as enabling in the context of SUD and OUD. Nor do these solutions assist grandfamilies in readjusting the hierarchies and interaction patterns necessary for grandparents to assume a parenting role or for parents to resume their roles, if safe and appropriate.

Finally, given the importance of the family system to individuals' well-being, a systemic perspective requires consideration of how grandfamily dynamics, namely interaction patterns, boundaries, and hierarchies, may amplify or attenuate parental opioid misuse (Minuchin 1985). Kroll (2007) theorizes that the family can be both a cause and solution for substance misuse, though these processes are significantly influenced by the societal contexts, including those discussed previously, in which the family is embedded. As a causal influence that is not without controversy, parental substance misuse has been associated with offspring's own substance misuse (Kroll 2007). In some cases, family members are even a source for access to drugs like prescription opioids (Rigg et al. 2018). While the pathways of the intergenerational transmission of substance misuse are highly complex, relevant relational dynamics 
could include poor parenting, insecure attachment relationships, family disruption and dissolution, and exposure to trauma and other adverse experiences (Kroll 2007). In fact, approximately $70 \%$ of people with SUDs have a history of trauma (Funk et al. 2003). Custodial grandparents and parents may also have problematic interaction patterns, perhaps rooted in long-standing conflicts or divided loyalties, that enable substance misuse (Kroll 2007). While these interaction patterns initially serve to maintain homeostasis within the grandfamily system, overly rigid or loose boundaries and inappropriate or inverted hierarchies can also contribute to individual substance misuse or maladaptive family responses. In contrast, when grandfamilies are able to adapt and establish new interaction patterns, they can become critical sources of support and encouragement for individuals pursuing treatment and maintaining recovery (Kroll 2007; Rigg et al. 2018).

\section{Grandfamilies and the Opioid Epidemic}

Despite the central role of substance misuse in the formation of grandfamilies, research on the impact of parental substance misuse, let alone opioid misuse, on grandparents raising grandchildren has been surprisingly limited. As noted, research on the topic began more than twenty years ago and focused on grandparents raising grandchildren in the context of the crack cocaine epidemic (e.g., Burton 1992; Minkler and Roe 1993; Minkler et al. 1992; Roe et al. 1994). Following a lull in research on the topic, there has been a recent increase in studies specifically examining parental substance misuse in grandfamilies (e.g., Anderson 2019; Davis et al. 2020; Gordon 2018; Hansen et al. 2020; O'Leary and Butler 2015; Taylor et al. 2016, 2017). The majority of this work has approached substance misuse broadly, with only a few studies focusing specifically on opioid misuse (e.g., Anderson 2019; Davis et al. 2020). Collectively, the older and more recent studies, which have utilized samples from the United States, United Kingdom, New Zealand, and Australia, are primarily qualitative and descriptive in nature. Topically, the studies have focused generally on the needs and experiences of custodial grandmothers and have not consistently parsed out the unique impacts of parental substance misuse on the grandparent, let alone other family members (e.g., grandchildren, parents, extended family members). What is needed is information about the distinctive consequences of parental opioid misuse for grandfamilies, including the consequences for their physical, psychological, and relational well-being.

With these limitations in mind, in the following sections, we provide a systemically informed (Minuchin 1985) review of the literature related to grandfamilies in the context of parental substance and opioid misuse. Given the overall lack of literature on the topic, our review includes empirical studies and conceptual works specifically focused on grandparents raising grandchildren and parental substance misuse, including opioid misuse. We organize our discussion of these works thematically, so as to emphasize major findings and to identify critical priorities for clinical intervention, policy, and future research.

\section{Assumption of Caregiving Responsibilities}

Within the context of parental substance misuse, Roe et al.'s (1994) seminal study established that assuming care of a grandchild is both a moment and a process, in that there is often a specific moment when the grandchild comes into the grandparent's care, but that the moment is often the culmination of a series of crises. Recently, Davis et al. (2020) also emphasized the process of assuming care, noting that due to the nature of OUD (i.e., overdose potential, suicidality, periods of use and abstinence), grandparents frequently find themselves navigating a series of crises. In this way, assuming responsibility for a grandchild highlights the interconnections among family members, including the bidirectional nature of the grandparent-parent relationship (Minuchin 1985). Overall, taking responsibility for a grandchild due to parental substance misuse can be gradual or sudden, planned or unplanned, voluntary or obligatory, and formal (i.e., involving child welfare authorities) or informal (i.e., assuming nonlegal custody) (Barnard 2003; Gordon 2018; Kroll 2007; Lange and Greif 2011). Studies also reveal variation in the degree to which grandparents initiate their caregiving responsibilities and how collaboratively they work with parents, which likely reflects existing family interaction patterns and hierarchies (Gordon 2018; Roe et al. 1994). For example, in a study of 88 Australian custodial grandparents, Taylor et al. (2017) found that some parents had voluntarily relinquished responsibility for the care of their children to grandparents, while other situations involved the grandparents or child welfare authorities removing children from the parents' care.

In their groundbreaking study of 71 African American grandmothers raising grandchildren due to parental crack cocaine misuse, Roe et al. (1994) identified three patterns in grandmothers' assumption of caregiving responsibilities. First is the sudden assumption of care, which resulted from a crisis (e.g., overdose or incarceration) that rendered the parent unavailable. In a more recent qualitative study of 15 grandparents raising grandchildren due to parental opioid misuse, Davis et al. (2020) similarly found that grandparents were unprepared to care for their grandchildren and had to make arrangements quickly, even though some anticipated raising their grandchildren. The second pattern identified by Roe et al. (1994) is a negotiated assumption of care, whereby grandmothers and parents worked together to arrange the 
grandchild's care while the parent sought treatment. Over time, however, these grandmothers realized that the parents would be unable to care for their children. The final pattern is the inevitable assumption of care, in which grandmothers took on increasing responsibility for their grandchildren (Roe et al. 1994). While these situations were tenuous all along, grandmothers described an event that "crosses the line" (p. 293) and triggered them to remove their grandchildren from the parents' care or to notify the police or child welfare authorities (Roe et al. 1994). More recently, Taylor et al. (2016), in a study of 49 Australian grandmothers, also found that grandmothers would take a "tough love" (p. 945) approach by giving ultimatums to their grandchildren's parents about getting treatment. If the parents did not pursue treatment and demonstrate an ability to care for their children, or if there was concern that the children would come to the attention of the child welfare authorities, grandparents would take over care of the grandchildren (Taylor et al. 2016). Systemically, these patterns demonstrate how grandparents and parents are deeply intwined in grandfamilies impacted by substance misuse, as well as the inherent variation in how individual grandfamilies navigate the substance misuse-related perturbations to the family system.

Whatever the pattern of assuming caregiving responsibilities, raising grandchildren is often a long-term commitment of 5 years or more (US Census 2020b) that impacts all facets of grandparents' lives. While recent studies reveal that grandparents are willing to undertake this role to ensure the safety and well-being of their grandchildren (Haglund 2000; O'Leary and Butler 2015; Taylor et al. 2017), it is still an "off time" role that disrupts homeostasis within the larger grandfamily system, in the sense that grandparents are assuming caregiving responsibilities during a time of their lives when they did not plan to be raising children (LandryMeyer and Newman 2004; O'Leary and Butler 2015). Other hallmarks of the role include role ambiguity, in terms of being both grandparent and parent to the grandchild, and role conflict related to balancing the demands of raising a grandchild with other responsibilities such as work or family caregiving (Landry-Meyer and Newman 2004; Lange and Greif 2011). It is these aspects of the grandparent role, along with challenges specific to parental substance or opioid misuse, that can create stress and negatively impact grandparents' health and well-being.

\section{Grandparent Stress and Well-Being}

Grandparents raising grandchildren experience multiple stressors that can compromise their physical and psychological well-being. Commonly referenced stressors, in studies specific to parental substance misuse, include financial distress related to providing for the grandchild, legal difficulties associated with gaining custody, social isolation from friends, and inadequate housing (Davis et al. 2020; Gordon 2018; Minkler et al. 1994; O'Leary and Butler 2015; Taylor et al. 2017; Templeton 2012). Other stressors, specific to parental substance misuse, include the possibility of multiple family members being engaged in substance misuse (Roe et al. 1996), exposure to drug-trade-related crime (Burton 1992), living in underserved or dangerous communities (Hansen et al. 2020), and problematic family dynamics (Barnard 2003). Numerous scholars have suggested that parental substance misuse amplifies existing stressors, which further erodes grandparents' well-being and results in negative outcomes (e.g., Engstrom 2008; Gordon 2018; Haglund 2000; Hansen et al. 2020), although this assertion has not been examined empirically. One mechanism for this potential linkage may be chronic stress, given findings that grandparents navigate multiple crises when their grandchild's parents are misusing substances (Davis et al. 2020). Another may be an accumulation of risk, such that early trauma and adversity, structural inequalities (e.g., class, race, and gender-related disparities), and environmental stressors (e.g., poverty) result in cumulative disadvantage that increases grandparents' vulnerability to adverse outcomes (DolbinMacNab and Few-Demo 2018; Engstrom 2008; Ferraro and Shippee 2009). Systemically, grandparents' negative outcomes can be conceptualized as arising from problematic family interaction patterns and maladaptive responses to the parental substance misuse (Minuchin 1985).

Studies consistently find that grandparents raising grandchildren experience negative physical and mental health outcomes. Psychologically, grandparents report high rates of depression, anxiety, and psychological distress (Hayslip et al. 1998; Minkler et al. 1997; Musil et al. 2009). For physical health, the evidence is mixed, with some studies finding increased functional limitations and disease burden (e.g., diabetes, hypertension) and others suggesting that grandparents' physical health problems are due to poverty, pre-existing health conditions, caregiving intensity, and race-related health disparities (Hughes et al. 2007; Minkler and Fuller-Thomson 1999; Minkler et al. 1992; Musil et al. 2010; Roe et al. 1996; Whitley and Fuller-Thomson 2017). Among grandparents raising grandchildren due to parental substance misuse, older and more current studies of African American and Appalachian grandparents find that grandparents often downplay their own health concerns or delay their own medical appointments because of the demands of caregiving or because they are prioritizing their grandchild's health and medical care (Hansen et al. 2020; Minkler et al. 1992; Roe et al. 1996).

Despite these physical and mental health challenges, grandparents raising grandchildren are resilient. Broadly, personal attributes (e.g., resourcefulness, empowerment, positive appraisals), adaptive processes (e.g., active coping or problem-solving), and other protective factors (e.g., social 
support, spirituality) can reduce grandparents' vulnerability to negative outcomes (for a summary, see Hayslip and Smith 2013). Within the context of parental substance misuse, Taylor et al. (2016)'s interviews with 49 Australian grandparents revealed post-traumatic resilient growth, in that grandparents shifted from a negative to a positive future outlook for themselves and their grandchildren. Some grandmothers also reported engaging in advocacy for other grandfamilies (Taylor et al. 2016). Additionally, in their seminal study of 71 African American grandmothers raising grandchildren due to parental crack cocaine misuse, Minkler et al. (1994) found that grandmothers managed stress by accessing emotional support and instrumental assistance from friends and family. While these studies illuminate resilience among grandparents impacted by parental substance misuse, more information about their resilience within the unique context of parental opioid misuse is needed.

\section{Caring for Vulnerable Grandchildren}

Children residing with parents who misuse substances are at risk for exposure to numerous adverse and traumatic events. These include experiencing maltreatment in the form of abuse or neglect, witnessing intimate partner violence, and being exposed to dangerous living situations or associates of their parents (Haglund 2000; Seay and Kohl 2015; Smith and Wilson 2016; Taylor et al. 2016, 2017). Financial insecurity, unstable housing, and food insecurity are also common when parents misuse substances, as parents cannot maintain employment and may spend available money on drugs (Feder et al. 2018). In studies of grandfamilies, grandparents reported that their grandchildren's parents purchased drugs with money they obtained from selling goods (e.g., diapers and formula) or with financial benefits intended for the grandchild (Haglund 2000; Roe et al. 1994; Taylor et al. 2016). Relationally, substance misuse may prevent parents from connecting with their children, such that parents may fail to respond to their children's cues, be unable to form attachment bonds, employ poor parenting skills, or be impaired when their children need their attention (Feder et al. 2018; Mirick and Steenrod 2016). Additionally, parent-child relationships may be marked by diffuse boundaries and inverted hierarchies (Minuchin 1985). Collectively, these and other problematic parent-child interaction patterns can impact a child's ability to relate to and trust others, including their custodial grandparents (Kroll 2007; Lander et al. 2013; Mirick and Steenrod 2016). Finally, children living in homes with active parental substance use are at increased risk for poisoning or overdose, as a result of accidentally ingesting or experimenting with substances (Feder et al. 2018). The likelihood of grandchildren experiencing these and other adversities is increasingly being documented within the broader grandfamilies literature, with one recent study finding that approximately $50 \%$ of adolescent grandchildren had experienced four or more adverse childhood experiences (Smith, Infurna, et al. 2019) and another suggesting that almost $75 \%$ of grandchildren have had some type of trauma exposure (Sprang et al. 2015).

Parental opioid misuse can also negatively impact children's development, especially in the case of prenatal drug exposure. Mothers who misuse opioids during pregnancy are likely to have children born preterm, at a lower birthweight, with a lower head circumference, or with congenital anomalies; these children may also experience Neonatal Abstinence Syndrome or Neonatal Opioid Withdrawal Syndrome (NAS/NOWS; Honein et al. 2019; Patrick and Schiff 2017). NAS/NOWS are the formal diagnoses for an infant's withdrawal from the substances they were exposed to prenatally and include symptoms such as tremors, seizures, excessive and uncontrollable crying, feeding and breathing problems, and an overall inability to be soothed (Kocherlakota 2014). Infants diagnosed with NAS/NOWS are at increased risk for sudden infant death syndrome (SIDS), jaundice, and seizures, and they may have difficulty meeting developmental milestones, experience speech or language problems, hearing or vision difficulties, and behavior problems (Kocherlakota 2014; Patrick and Schiff 2017).

Long-term, prenatal exposure to substances and the adversities and traumatic experiences associated with parental substance misuse have been linked to a variety of deleterious outcomes. Children may experience internalizing and externalizing problems such as anxiety, depression, attention deficit/hyperactivity disorder (ADD/ADHD), oppositional defiant disorder (ODD), and conduct disorder (CD; Sheridan 2014; Smith and Wilson 2016). Survey findings, from a sample of New Zealander grandparents, suggest that these diagnoses are commonly reported by custodial grandparents whose grandchildren have experienced parental substance misuse (Gordon 2018). Grandparents in this study also reported diagnoses of autism, attachment disorder, and post-traumatic stress disorder and struggled to manage their grandchildren's aggressive, risky, violent, or destructive behavior (Gordon 2018). In their study of Appalachian grandparents raising grandchildren due to parental substance misuse, grandparents also worried about their grandchildren eventually misusing substances themselves (Hansen et al. 2020). Beyond these outcomes, children raised in homes with parental substance misuse often receive inadequate medical and dental care, which can have long-term implications for their overall health (Smith and Wilson 2016). Additionally, children exposed to parental substance misuse may experience academic difficulties such as truancy, learning difficulties, and other academic problems (Mirick and Steenrod 2016; Smith and Wilson 2016). It is important to note that, while these negative outcomes likely 
reflect elements of parental substance misuse, they may also reflect environmental adversities and other sources of marginalization.

The difficulties experienced by children exposed to parental substance misuse helps to explain consistent evidence that, in comparison to children from representative samples and those living in other family constellations, children raised by grandparents fare worse in terms of psychological, physical, and scholastic outcomes (Bramlett and Blumberg 2007; Pilkauskas and Dunifon 2016; Smith, Hayslip, et al. 2019a, b; Smith and Palmieri 2007; Ziol-Gust and Dunifon 2014). While none of these studies explicitly considered the role of parental substance misuse, findings suggest that between 20 and $30 \%$ of grandchildren had clinically elevated levels of psychological difficulties, including significantly higher levels of emotional symptoms, conduct problems, hyperactivity and inattention, and peer problems (Kelley et al. 2011; Smith, Hayslip, et al. 2019a, b; Smith and Palmieri 2007). And, compared to children in other family constellations, Bramlett and Blumberg (2007) found that, after controlling for sociodemographic characteristics, children raised by grandparents had the worst physical health and, compared to children living with two biological parents, had greater special health needs, ADD/ADHD, and serious emotional and peer difficulties. More recently, Ziol-Guest and Dunifon (2014) found that children in grandfamilies had the highest rates of mental health problems and elevated rates of poor physical health and limiting conditions. Similarly, when compared to children living with mothers, children raised by grandparents had more externalizing problems and symptoms of ADD/ADHD, as well as poorer academic performance (Pilkauskas and Dunifon 2016). Collectively, these studies underscore the idea that children raised by grandparents, many of whom are exposed to substance misuse, can be defined as vulnerable.

In studies specific to grandparents raising grandchildren in the context of parental substance misuse, grandparents consistently identify their grandchildren's difficulties as a significant source of stress (Barnard 2003; Davis et al. 2020; Haglund 2000; Minkler et al. 1994; Roe et al. 1994, 1996; Templeton 2012). Raising children for a second time is stressful enough, due to the generation gap and the time and energy demands of parenting, but parenting stress can be exacerbated by grandchildren's disruptive or difficult behavior (Dolbin-MacNab 2006; Doley et al. 2015; Kelley et al. 2013; Goodman 2012; Sprang et al. 2015). Systemically, it requires grandparents to establish a clear hierarchy and boundaries with their grandchildren, and consider the function of the grandchild's behavior within the family system, which can be a challenge. Additionally, when grandchildren have significant behavioral difficulties or require specialized care, grandparents may struggle to obtain medical and psychological services, partner with schools to address their grandchildren's needs, and find respite care or childcare (Davis et al. 2020; Gordon 2018; O'Leary and Butler 2015).

Beyond the demands of parenting, grandparents must manage their grandchildren's relationships with their parents. When it comes to grandchild-parent interactions in the context of parental substance misuse, Taylor et al. (2017)'s study of 88 Australian grandmothers found that grandparents report feeling torn between protecting their grandchildren from harmful interactions with parents, while still facilitating some type of relationship and contact. While studies specific to the impact of parental substance misuse consistently find that grandparents prioritize the safety and well-being of their grandchildren over facilitating the parent-grandchild relationship (Haglund 2000; O'Leary and Butler 2015; Taylor et al. 2017), contact still occurs and is inherently complicated. For instance, in a study of 21 English grandparents, Templeton (2012) found that grandparents experienced difficulties talking to their grandchildren about their parents' substance misuse, often feeling uncertain about how to balance their desire to be honest with their fear of harming or frightening their grandchildren. Fortunately, these grandparents generally understood the importance of clear boundaries by not "bad mouthing" their grandchildren's parents (Templeton 2012), which is critical given evidence that grandchildren have strong feelings of love and loyalty toward their parents, despite the circumstances (DolbinMacNab and Keiley 2009; Dunifon et al. 2016). Maintaining this "neutral" stance may be difficult for grandparents, especially for those who are under significant stress and who are experiencing their own reactivity toward their grandchildren's parents.

Grandparents must also assist their grandchildren in adjusting to living with the grandparent versus the parent (Kroll 2007). Depending on how long the grandchild had been living with their parent(s) and the nature of those living arrangements, transitioning to a grandparents' home may be difficult; grandchildren may struggle to follow their grandparents' rules, especially if they were not used to expectations, discipline, and parental monitoring. In cases where grandchildren were unsupervised or parentified, both signs of inappropriate boundaries and hierarchy within the parent-child subsystem, they could struggle with a loss of freedom and their adult role (Kroll 2007; O'Leary and Butler 2015). Grandchildren's disrupted attachment bonds and post-traumatic stress disorder may also be expressed during the grandchild's transition to residing with the grandparent (Kroll 2007; Sprang et al. 2015). When parents are in contact, but even if they are not, grandchildren can experience loyalty conflicts or confusion over who ultimately has parental authority over them (Dolbin-MacNab and Keiley 2009; Dolbin-MacNab et al. 2009; Dunifon et al. 2016; Kroll 2007). Grandchild ambivalence is also common, in that grandchildren recognize the benefits of living with their 
grandparents, while still missing their parents, blaming the grandparent for "taking" them, or expressing a preference to live with their parents (Dolbin-MacNab and Keiley 2009; Dolbin-MacNab et al. 2009; Dunifon et al. 2016). Emotionally, grandchildren may experience anger, loss, and worry about their parents' safety and well-being. Grandparents must acknowledge and help their grandchildren navigate these complex emotions, all while establishing new boundaries, hierarchies, and patterns of interacting within the grandparent-grandchild subsystem.

Despite the challenges, grandparents and grandchildren report benefits associated with their family constellation. Studies focused on parental substance misuse find that grandparents view raising their grandchildren as being worth the challenges because they are keeping their grandchildren safe and providing them with the best chance at life (Burton 1992; O'Leary and Butler 2015; Minkler et al. 1994). Grandparents in these studies also report that their grandchildren are a source of pride and love, and describe how raising them provides a sense motivation and a reason for persevering through challenges (Burton 1992; Davis et al. 2020; O'Leary and Butler 2015). For their part, grandchildren reveal that the benefits of being raised by a grandparent include instrumental and emotional support and the chance for a better life trajectory (Dolbin-MacNab and Keiley 2009; Dolbin-MacNab et al. 2009). To that end, children in kinship care have longer and more stable placements than children in non-relative care, though more work is needed to understand the nuances of why and for whom (Font 2015; Kimberlin et al. 2009). Furthermore, while Wu et al. (2015) suggest that, compared to children in non-kinship care, children in kinship care have lower internalizing, externalizing, and overall behavior problems, this may depend on the quality of the care environment, caregiver and child mental health, and neighborhood characteristics, among other factors (Xu and Bright 2018).

\section{Navigating Relationships with Parents}

In the context of opioid or substance misuse, grandparents' feelings toward their adult children (i.e., their grandchildren's parents) tend to be complex and marked by ambivalence. Across multiple studies, grandparents report worrying about the health and safety of their adult children, particularly in terms of the fear of suicide or overdose, incarceration, or long-term negative health consequences of substance misuse (Barnard 2003; Haglund 2000; Hansen et al. 2020; O'Leary and Butler 2015). For grandparents, witnessing their adult children struggle with substance misuse was emotionally painful (Barnard 2003; Haglund 2000), yet they remained hopeful (at first) for their adult child's recovery and eventual reunification with the grandchild (Davis et al. 2020). Grandparents demonstrated their concern by making efforts to assist their adult children and grandchildren, perhaps as a strategy to maintain family homeostasis. For example, in a study of 15 grandmothers raising grandchildren due to parental opioid misuse, Davis et al. (2020) found that grandmothers tried to avoid involving the authorities (e.g., police or child welfare), so as to not make things worse for their adult children. Similarly, in Haglund's (2000) study of 6 African American grandmothers raising grandchildren whose parents misused cocaine, grandmothers offered their adult children money for the grandchild's care, tried to help the parent get into treatment or abstain from drugs, or allowed the parent and grandchild to live in their home. In a study of 62 Scottish parents with histories of substance misuse, parents confirmed that grandparents supported them by providing childcare and basic necessities (e.g., food and shelter) and paying for treatment (Barnard 2003).

When parents continued to misuse substances, grandparents' supportive actions and feelings of concern shifted to anger, disappointment, and resentment over their adult children's inability to fulfill their parental responsibilities and the negative impact on the grandchildren (Haglund 2000; Hansen et al. 2020; O'Leary and Butler 2015; Templeton 2012). In Roe et al.'s (1994) study, grandparents felt taken advantage of by their adult children, who they perceived as continuing to live their lives without accepting the responsibilities of parenthood. Other studies reveal that grandparents shifted to more extreme strategies with their adult children including giving "tough love," confronting the parent, allowing the parent to "hit rock bottom," abandoning the parent, or taking the parent to court to terminate their parental rights (Haglund 2000; Taylor et al. 2016, 2017). Ultimately, grandparents often made the difficult decision to prioritize the safety and well-being of their grandchildren over their adult children (Haglund 2000; O'Leary and Butler 2015; Taylor et al. 2017). For these grandparents, there was grief and loss in making this decision, as well as an understanding that their relationship with their adult child was irrevocably damaged (Taylor et al. 2016).

While there is limited research on the experiences of parents, grandparents report that their relationships with their adult children range in quality from amicable to conflictual to hostile (O'Leary and Butler 2015; Taylor et al. 2017; Templeton 2012). When relationships were amicable, parents expressed gratitude (and guilt and shame) related to grandparents' support, and recognized that they needed treatment and were not in a position to care for their children (Barnard 2003). In these cases, it has been hypothesized that the grandparents' assistance facilitated the parents' ability to seek treatment (Kroll 2007). When the relationship was hostile, parents described how grandparents dismissed and undermined their efforts as a parent, blocked their contact with their children, and treated them in a disapproving manner (Barnard 2003). These dynamics within the 
grandparent-parent subsystem have been conceptualized as reflecting underlying problematic interaction patterns (Barnard 2003; Kroll 2007); systemically, parental substance misuse serves a function within the family system and the difficult relationship between grandparents and parents reflects long-standing, recursive patterns of interaction.

Interestingly, some parents in Barnard's (2003) study indicated that the assistance they received from the grandparent facilitated their substance misuse, as it gave them the freedom to continue misusing substances. This notion was not lost on grandparents, as grandparents across multiple studies reported worrying that their assistance was enabling their adult children (O'Leary and Butler 2015; Templeton 2012). Kroll (2007) extends this discussion by suggesting that custodial grandparents may interfere with parents' recovery by being in denial about the parents' substance misuse, colluding with problematic behavior, or preventing parents from resuming a parental role. In this sense, Kroll (2007) questions the extent to which custodial grandparents are facilitating (versus interrupting) parental substance misuse. Systemically, enabling behavior may reflect grandparents' attempts to maintain homeostasis, as well as diffuse boundaries or excessive assertion of power or authority within the grandparent-parent subsystem.

As a result of these relational dynamics, it is not surprising that parental contact is a point of stress for custodial grandparents. While some parents are completely absent, studies find that many have an inconsistent or unpredictable pattern of contact (Gordon 2018; O'Leary and Butler 2015; Taylor et al. 2016, 2017). When parents are in contact, grandparents report difficulties with unannounced visits, abusive and hostile behavior, theft of money or property, exposure to criminal behavior, and broken promises to grandchildren (Haglund 2000; O'Leary and Butler 2015; Taylor et al. 2016). Grandparents also express concerns about the impact of intoxicated or impaired parents on the grandchildren (Gordon 2018; O'Leary and Butler 2015). Additional stressors include extended family (e.g., spouses, adult children) conflict, rooted in the family's interaction patterns, over the parents' involvement in the family and the assistance the parent is receiving from the grandparent (Barnard 2003; Taylor et al. 2017; Templeton 2012). To manage these challenges, Lange and Greif (2011) revealed, in study of 11 grandmothers raising children of mothers with SUD, that grandmothers reduced stress and protected themselves and their grandchildren by setting boundaries with parents. However, setting firm yet flexible boundaries and asserting appropriate authority can be difficult for grandparents, especially if it is a new way of interacting with the parent. Setting boundaries can also activate grandparents' fears of parents taking the grandchild back-a particular concern for grandparents without legal relationship to their grandchildren (Davis et al. 2020; Taylor et al. 2017).
A final consideration related to the grandparent-parent relationship is the issue of reunification. While reunifying children with their parents is a primary goal of the child welfare system, it is not always possible (Kimberlin et al. 2009). Reunifications are more likely to be successful when parents have adequately addressed their substance misuse and any related challenges such as mental illness (for a detailed discussion, see Kimberlin et al. 2009). That said, reunification may be difficult due to grandparent-parent conflict and grandparent reluctance to return the grandchild to the parents' care (Barnard 2003; Dolbin-MacNab et al. 2020; Taylor et al. 2017). The degree of grandparent involvement in the reunification may be relevant to its success as well. For instance, Blakey's (2012) study revealed that greater support provided by grandparents decreased the likelihood of reunification among African American women with histories of substance misuse. In contrast, Dolbin-MacNab et al. (2020) found that grandmother involvement was critical to a successful reunification, especially when grandmothers provided their adult children with instrumental and emotional support.

\section{Contextual Stressors: Societal Stigma and Barriers to Service}

In accordance with a systemic perspective (Minuchin 1985), custodial grandparents and grandchildren interact with and are embedded in larger systems or contexts that influence their health and well-being. Most relevant to grandfamilies who have experienced parental substance and opioid misuse is societal stigma related to their family structure and to substance misuse. Regarding their family structure, stigmatizing assumptions include the ideas that grandparents (a) have failed as parents and will fail with their grandchildren, (b) are too old to be raising children, (c) bear responsibility for their situations, or (d) caused the parents' difficulties (Dolbin-MacNab 2015; Gibson 2002; Hayslip and Glover 2008; Hayslip et al. 2009; Kroll 2007). When this stigma is combined with the previously discussed stigma associated with substance misuse, it is not surprising that grandparents feel judged by family, friends, community members, and professionals (Crittenden et al. 2009; Roe et al. 1996; Templeton 2012). In fact, research on attitudes toward custodial grandparents reveals that young adults and traditional grandparents have more negative perceptions of grandparents when the reasons for caregiving are less socially acceptable (i.e., substance misuse, child maltreatment; Hayslip and Glover; Hayslip et al.). In this sense, grandfamilies experience compounding stigma which, if experienced in multiple contexts over time, can result in increased feelings of shame, guilt, and embarrassment (Engstrom 2008; Minkler et al. 1994; Roe et al. 1996). That said, Hansen et al. (2020) conclude that stigma and associated negative feelings may decline 
when substance misuse and custodial grandparenting is common within a grandparent's community. Unfortunately, when stigma remains high, it may reduce grandparents' willingness to seek services for themselves, their grandchildren, and their grandchildren's parents (Engstrom 2008).

If grandparents attempt to seek services, they are likely to encounter numerous barriers. In studies focused on grandparents who are raising grandchildren due to parental substance or opioid misuse, grandparents reported a lack of awareness of available services, dissatisfaction with the amount or type of services available, and frustration with the lack of collaboration across agencies and services (Davis et al. 2020; O'Leary and Butler 2015; Templeton 2012). They also expressed frustration over the lack of prevention and treatment services for substance misuse, particularly among those who resided in rural or underserved areas (Hansen et al. 2020; Mignon and Holmes 2013). Additional barriers to obtaining services included prohibitive costs, lack of legal authority, fear of harming the parent, and privacy concerns, among others (e.g., lack of transportation or childcare; Crittenden et al. 2009; Davis et al. 2020).

For those grandparents who access services, an additional barrier is professionals who hold stigmatizing attitudes towards grandfamilies and substance misuse (DolbinMacNab 2015; Gibson 2002; O'Leary and Butler 2015; Roe et al. 1994). For instance, Roe et al. (1994) found that grandmothers experienced frustration with getting social services to intervene when their grandchildren were in danger, believing that their concerns were not being taken seriously. In O'Leary and Butler's (2015) study of 10 Irish grandparents raising grandchildren of parents with SUD, grandparents reported that professionals took their efforts with their grandchildren for granted, showed them little empathy, and treated them as if they did not deserve assistance due to assumed family dysfunction or the belief that they were ineffective parents. Unfortunately, when grandparents experience professionals who hold stigmatizing attitudes, there is increased risk for a strained professional relationship, poor quality services, or not receiving services at all (Berrick et al. 1994; Gibson 2002; Hayslip and Glover 2008).

\section{Priorities for Future Research}

Given the paucity of research on grandfamilies within the context of the opioid epidemic, there are several priorities for future research. First, descriptive studies are needed to identify the scope of the issue-that is, how many grandfamilies have been impacted by parental opioid misuse and OUD, as well as their demographic characteristics. In these studies, special attention should be given to including grandparents who are raising their grandchildren outside of the child welfare system. More broadly, all grandfamilies researchers should explicitly identify the reasons that the grandparents in their samples are raising their grandchildren, regardless of whether or not the study focuses on parental substance misuse. While this could prove challenging due to the multiple, interrelated reasons for caregiving within grandfamilies (Haglund 2000; Hayslip et al. 2017; Taylor et al. 2016), providing this context would help distinguish grandparent and grandchild experiences, needs, and outcomes that are specific to parental opioid or substance misuse versus other reasons for caregiving (e.g., parental incarceration, abandonment, physical or mental health difficulties, etc.).

Although a systemic perspective emphasizes that parental substance misuse impacts the entire grandfamily system (Minuchin 1985), existing research has not fully embraced this perspective. Therefore, another priority for future research is determining the impact of parental opioid and substance misuse on grandparent and grandchild physical and mental health outcomes, both in the immediate and the long-term. Impacts on other family members should be investigated as well. Within these studies, special consideration should be given to transgenerational family processes (e.g., grandparent-parent conflict, boundaries, communication patterns, etc.) and contextual factors (e.g., availability of informal and formal supports, financial strain, health disparities, etc.) that may predict physical and mental outcomes. Relatedly, future research should also explore the personal attributes, adaptive processes, and protective factors that may promote resilience in grandfamilies impacted by parental opioid and substance misuse. Based on previous research on grandfamilies in the context of substance misuse, worthy constructs for investigation could include resourcefulness, empowerment, active coping, social support, and optimism or benefit finding (Hayslip and Smith 2013; Minkler et al. 1994; Taylor et al. 2016). Facets of family resilience should also be identified and considered.

Finally, given evidence that grandfamilies experience significant stigma and barriers to accessing services (Crittenden et al. 2009; Davis et al. 2020; Hansen et al. 2020; Mignon and Holmes 2013; O'Leary and Butler 2015; Templeton 2012), future research should examine grandfamilies' service experiences, especially with regard to parental treatment for opioid or substance misuse and services for grandchildren's emotional and behavioral difficulties. Additionally, researchers could explore best practices for working with grandfamilies impacted by parental opioid or substance misuse, particularly practices or interventions that incorporate the various subsystems within the family (e.g., grandparent-parent, parent-grandchildren, grandparent-grandchild), address problematic family interaction patterns, and account for the family's history of trauma and other adversities. Finally, future research should identify best practices for facilitating productive grandparent-parent relationships and 
parental contact, when appropriate, and examine interventions that support parent-child reunification.

\section{Clinical Implications for Grandfamilies}

While a full discussion of treatment for OUD is beyond the scope of this paper, our review highlights several directions for systemically informed (Minuchin 1985) clinical intervention with grandfamilies impacted by parental OUD and opioid misuse. Fundamentally, to address their short- and long-term needs, grandfamilies need a comprehensive range of services (Crittenden et al. 2009; Davis et al. 2020; Templeton 2012). Potentially beneficial services would include low-cost legal services, housing assistance, respite care, case management, social support (e.g., support groups), psychoeducation on OUD and SUD, and financial assistance. Grandparents and grandchildren could also benefit from mental health treatment; grandparents may need to process their feelings about their circumstances, receive parenting guidance, reflect on their relationship with the grandchild's parent, or improve stress management. In addition to addressing any emotional or behavioral difficulties, grandchildren may benefit from processing their feelings about their family and addressing the issues that brought them into their grandparents' care. Beyond the obvious need for treatment and recovery services, parents could benefit from services related to early intervention, relapse prevention, employment assistance, housing assistance, parent training, as well as family-based services that promote a productive grandparent-parent relationship as well as parent-child bonds and reunification, if safe and appropriate (Engstrom 2008; Mirick and Steenrod 2016; Taylor et al. 2016, 2017).

From a systemic perspective, efforts must be made to improve grandparents' interactions with the larger environments in which they are embedded. For instance, even if services are available, grandfamilies experience barriers to accessing needed supports (Crittenden et al. 2009; Davis et al. 2020; Hansen et al. 2020; Mignon and Holmes 2013; O'Leary and Butler 2015; Templeton 2012). Therefore, efforts should be made to reduce key barriers to service utilization including lack of awareness of services, difficulties navigating service requirements, and logistical (e.g., transportation and childcare) challenges. In addition, services should be culturally attuned and responsive to the needs of specific communities of grandfamilies (Crittenden et al. 2009; Mignon and Holmes 2013). Finally, integration of child welfare services and treatment/recovery services could provide grandfamilies with a more efficient and coordinated service experience (O'Leary and Butler 2015).

Societally, stigma is a unique barrier to service utilization. Given that grandfamilies impacted by the opioid epidemic are likely to experience stigma related to both their family structure and opioid misuse (Engstrom 2008; Crittenden et al. 2009; Gibson 2002; Hayslip and Glover 2008; Hayslip et al. 2009; Roe et al. 1996; Taylor et al. 2017; Templeton 2012), efforts are needed to reduce both types of stigma. These efforts could include education initiatives focused on dispelling myths about opioids and opioid misuse, treatment, and recovery, especially among those communities and institutions with which grandparents are likely to interact (e.g., churches, schools, etc.; Vincenzes et al. 2019). Importantly, the use of person-first or non-judgmental language, with regard to people who experience OUD and SUD, should be an essential feature of all initiatives and services. Related to stigma specific to grandfamilies, education initiatives should address grandfamily strengths (and not just challenges) and confront misconceptions about family dysfunction or grandparents' suitability for raising grandchildren. Engaging key community informants, and incorporating the voices of grandparents, would be valuable in ensuring the validity and effectiveness of any initiative designed to reduce stigma.

As grandfamilies often experience stigma from the professionals with whom they come into contact (Gibson 2002), professionals could also benefit from education on the impacts of SUD and OUD on families generally, and the unique needs and experiences of grandfamilies impacted by the opioid epidemic (Crittenden et al. 2009; Taylor et al. 2016). In particular, professionals in law enforcement, the child welfare system, and the judicial system would benefit from this type of education. All professionals should also be encouraged to engage in critical self-reflection about their biases and assumptions about grandfamilies and individuals living with OUD, so that they can ensure that these beliefs do not negatively impact grandfamilies' service experience (Dolbin-MacNab 2015). Finally, explicit attention should be given to building strong, trusting professional relationships with grandparents, as these are often critical to rural grandfamilies and grandparents from historically marginalized groups (Crittenden et al. 2009).

Regardless of the exact approach to intervention, the traumatic circumstances underlying the formation of many grandfamilies, especially those impacted by parental opioid misuse, suggest the need for a trauma-informed approach to intervention. Fundamentally, this approach requires understanding the impact of trauma on all members of the grandfamily, recognizing signs of trauma in grandparents, parents, and grandchildren, and using trauma-informed principles to guide service delivery so as to avoid re-traumatization (SAMHSA 2014). Grandfamilies impacted by parental substance and opioid misuse are likely to benefit from the trauma-informed principles of safety, trustworthiness and transparency, peer support, collaboration and mutuality, empowerment, and cultural attunement (SAMHSA 2014). Intervention programs should apply these principles to all 
aspects of service delivery, including program policies and operations, as well as screening, assessment, and treatment.

Finally, the systemic emphasis on the role of the family in shaping outcomes suggests that grandfamilies would benefit from family-based approaches to intervention (Engstrom 2008; Gordon 2018; Kroll 2007; Minuchin 1985; Vincenzes et al. 2019). Family-based interventions, such as family therapy, are effective in supporting individuals with the process of treatment and recovery from SUD (Stumbo et al. 2016; Vincenzes et al. 2019). However, family involvement can also be a source of strain and conflict, and can interfere with recovery (Stumbo et al. 2016). Given the often-difficult relational history between grandparents and parents, careful assessment would be needed before proceeding with a family-based approach to treating a parent's OUD. Family therapy or other family-based approaches can also help grandfamilies navigate their unique relationships. For instance, treatment could focus on clarifying roles and boundaries between grandparents and parents, addressing problematic interaction patterns (e.g., divided loyalties, secrets, denial, conflicts), adjusting inappropriate hierarchies, reestablishing homeostasis, and building parent-grandchild bonds within the family (Engstrom 2008; Kroll 2007; Taylor et al. 2016, 2017). Grandparents and parents could also work on coparenting the grandchild, addressing past issues and relationship dynamics, and engaging in conflict resolution (Engstrom 2008). Family therapy could even help grandfamilies establish clear expectations and requirements for safe parent-child visitation or reunification.

\section{Policy Recommendations}

To best support grandfamilies impacted by the opioid epidemic, policy initiatives must respond to the unique needs of grandfamilies and to the opioid epidemic itself. Specifically, a systemically informed (Minuchin 1985) policy strategy that improves the quality of the larger contexts in which grandfamilies are embedded, and promotes family well-being, is essential to helping grandparents manage the demands of caregiving, ensure the safety of their grandchildren, and provide treatment and recovery supports for parents. One broad strategy for promoting these outcomes is policies that support the well-being of all families, including access to living wages, affordable medical and mental health care, safe and affordable housing, and low-cost, high quality childcare. To best support grandfamilies impacted by parental opioid misuse, policy initiatives should result in an integrated continuum of services that are responsive to both individual and family needs and that mitigate historic barriers to accessing services, especially among marginalized families. Moreover, given that the majority of interventions, such as wraparound services and intensive therapy, occur only after a crisis like a drug overdose or the removal of a child, policy initiatives should also emphasize prevention. With this approach, interventions can be moved upstream to encourage grandfamilies who are struggling to seek supportive services prior to a crisis or disaster that disrupts the family's stability and functioning.

Regarding policy priorities related to the opioid epidemic, policymakers should treat OUD and SUD as chronic diseases and focus on meeting the needs of individuals impacted by these diseases within the context of their families and communities. Specifically, policies should prioritize programs that offer treatment along the continuum of care, including harm reduction and early intervention, withdrawal management, immediate access to the level of treatment necessary for stabilization, and access to the duration of treatment necessary to promote and establish longterm recovery. In terms of adopting a systemically informed (Minuchin 1985) strategy, policies should support programs that emphasize family-based treatment versus approaches that isolate individuals and intentionally separate them from their children and familial supports. Currently, parents are often required to choose between parenting and treatment for their substance misuse, which can reduce treatment motivation, engagement, and retention. Relatedly, policies should also support early detection and treatment of OUD and SUD during pregnancy (Mihalec-Adkins et al. 2020). Pregnant women with OUD require added supports throughout their pregnancies and after the birth of their children. Unfortunately, most monitoring and supports drop off after delivery, leaving families to struggle with post-partum stressors, typical and atypical infant needs, and the recovery or substance misuse of one or both parents. Policy initiatives designed to support women with OUD or SUD, in the context of their families and parental roles and relationships, could reduce the number of children raised by grandparents, lessen the burden on the child welfare system, and promote family preservation.

Other policy recommendations related to the opioid epidemic include limiting and monitoring access to prescription opioids, diverting individuals from the criminal justice system, increasing access to substance treatment medications and overdose reversal drugs, promoting low-barrier harm reduction programs, and supporting public education campaigns to reduce stigma. As noted previously, policies that increase treatment options, especially in communities with limited access and resources, should be prioritized as well. Law enforcement and judicial policies should also be updated so that all SUDs, including OUD, are treated medically rather than criminally. In particular, parents should not be penalized for the method, duration, or type of treatment they receive for their OUD or SUD, especially when the legal and child welfare systems are setting milestones for reunification with their children. 
Specific to grandfamilies, grandparents would benefit from policies that support them in their roles and help them address the needs of their grandchildren. As grandfamilies often experience financial distress (Hayslip et al. 2017), increased financial assistance via improved access to Temporary Assistance to Needy Families (TANF), foster care maintenance payments, and other sources of financial support is needed. A second priority area would be earmarking funds, such as those available through the National Family Caregiver Support Program (NFCSP), for services for grandfamilies (Beltran 2018; Generations United 2018). These services could include kinship navigators, legal assistance, support groups, mental health care, or respite care. Policies also need to create supports, such as the ability to provide medical and educational consent for grandchildren and enhanced eligibility for services, for grandparents raising their grandchildren informally. All members of grandfamilies, whether or not they are involved in the child welfare system, should also have access to comprehensive, traumainformed services, including preventative, treatment, and recovery services that might facilitate family preservation. For those grandfamilies engaged with the child welfare system, foster care licensing standards need to be updated to ease the process of grandparents becoming licensed foster parents, which can also help them gain access to monthly stipends (Generations United 2018). Finally, and most broadly, a national policy strategy for supporting grandfamilies is needed; for example, Beltran (2018) has called for a national technical assistance center that would assist states and organizations in best practices for working with and supporting grandfamilies.

\section{Conclusion}

When parents are unable to care for their children as a result of opioid misuse or OUD, grandparents raising grandchildren serve as critical safety nets. While grandfamilies demonstrate considerable resilience in the face of a devastating public health emergency, they also face significant challenges that could benefit from support services. To promote the well-being of all members of grandfamilies, policy initiatives and interventions must focus on destigmatizing OUD and substance misuse, addressing trauma within the grandfamily system, and offering grandfamilies systemically informed (Minuchin 1985) services that address their individual needs and unique relationship dynamics, as well as the contexts in which they are embedded.

Funding No funding was received to assist with the preparation of this manuscript.
Data Availability Not applicable.

\section{Compliance with Ethical Standards}

Conflict of interest The authors have no conflicts of interest to declare that are relevant to the content of this manuscript.

Ethical Approval Not applicable.

Informed Consent Not applicable.

\section{References}

American Psychiatric Association (2013). Diagnostic and statistical manual of mental disorders $\left(5^{\text {th }}\right.$ ed.). American Psychiatric Association.

Anderson, L. (2019, April). Opioid prescribing rate and grandparents raising grandchildren: State and county level analysis [Poster]. Austin, TX: Population Association of America.

Annie E. Casey Foundation Kids Count Data Center. (2020). Children in the kinship care in the United States (2017-2019). https:// datacenter.kidscount.org/data/tables/10455-children-in-kinshipcare loc=1\&loct=2\#detailed/1/any/false/1757/any/20160,20161.

Baker, L., Silverstein, M., \& Putney, N. (2008). Grandparents raising grandchildren in the United States: Changing family forms, stagnant social policies. Journal of Sociology and Social Policy, 27(7), 53-69.

Barnard, M. (2003). Between a rock and a hard place: The role of relatives in protecting children from the effects of parental drug problems. Child and Family Social Work, 8(4), 291-299. https ://doi.org/10.1046/j.1365-2206.2003.00297.x.

Beltran, A. (2018). Supporting grandfamilies: Federal and state policy reforms. Grandfamilies, 5(2), 56-73. https://scholarworks.wmich .edu/grandfamilies/vol5/iss2/4.

Berrick, J. D., Barth, R. P., \& Needall, B. (1994). Comparisons of kinship foster homes and non-kinship foster homes. Children and Youth Services Review, 16(1-2), 33-63. https://doi. org/10.1016/0190-7409(94)90015-9.

Blakey, J. M. (2012). The best of both worlds: How kinship care impacts reunification. Families in Society, 93(2), 103-110. https ://doi.org/10.1606/1044-3894.4194.

Bozalek, V., \& Hooyman, N. (2012). Ageing and intergenerational care: Critical/political ethics of care and feminist gerontology perspectives. Agenda, 26(4), 37-47. https://doi.org/10.1080/10130 950.2012.755378.

Bullinger, L. R., \& Wing, C. (2019). How many children live with adults with opioid use disorder? Children and Youth Services Review, 104, 104381. https://doi.org/10.1016/j.childyouth 2019.06.016.

Bramlett, M. D., \& Blumberg, S. J. (2007). Family structure and children's physical and mental health. Health Affairs, 26(2), 549558. https://doi.org/10.1377/hlthaff.26.2.549.

Burton, L. M. (1992). Black grandparents rearing children of drugaddicted parents: Stressors, outcomes, and social service needs. The Gerontologist, 32(6), 744-751. https://doi.org/10.1093/geron $\mathrm{t} / 32.6 .744$

Case, A., \& Deaton, A. (2020). Deaths of despair and the future of capitalism. Princeton, NJ: Princeton University Press.

Centers for Disease Control and Prevention. (2019). Annual surveillance report of drug-related risks and outcomes. https://www. cdc.gov/drugoverdose/pdf/pubs/2019-cdc-drug-surveillancereport.pdf. 
Cicero, T. J., Ellis, M. S., Surratt, H. L., \& Kurtz, S. P. (2014). The changing face of heroin use in the United States: A retrospective analysis of the past 50 years. JAMA Psychiatry, 71(7), 821-826. https://doi.org/10.1001/jamapsychiatry.2014.366.

Crittenden, J., Adle, M., Kaye, L. W., \& Kates, B. (2009). Substance abuse exposure among youth being raised by grandparents in rural communities: Findings from a three-year evaluation. Journal of Intergenerational Relationships, 7(2-3), 291-305. https:// doi.org/10.1080/15350770902851312.

Davis, M. T., Warfield, M. E., Boguslaw, J., Roundtree-Swain, D., \& Kellogg, G. (2020). Parenting a 6-year old is not what I planned in retirement: Trauma and stress among grandparents due to the opioid crisis. Journal of Gerontological Social Work, 63(4), 295-315. https://doi.org/10.1080/01634372.2020.1752872.

Dolbin-MacNab, M. L. (2006). Just like raising your own? Grandmothers' perceptions of parenting a second time around. Family Relations, 55(5), 564-575. https://doi.org/10.111 1/j.1741-3729.2006.00426.x.

Dolbin-MacNab, M. L. (2015). Critical self-reflection questions for professionals who work with grandfamilies. Grandfamilies, 2(1), 139-159. https://scholarworks.wmich.edu/grandfamilies/ vol2/iss $1 / 6 /$.

Dolbin-MacNab, M. L., \& Few-Demo, A. L. (2018). Grandfamilies in the United States: An intersectional analysis. In V. Timonen (Ed.), Grandparenting practices around the world (pp. 189-208). Bristol: Policy Press.

Dolbin-MacNab, M. L., \& Keiley, M. K. (2009). Navigating interdependence: How adolescents raised solely by grandparents experience their family relationships. Family Relations, 58(2), 162-175. https://doi.org/10.1111/j.1741-3729.2008.00544.x.

Dolbin-MacNab, M. L., Rodgers, B. E., \& Traylor, R. M. (2009). Bridging the generations: A retrospective examination of adults' relationships with their kinship caregivers. Journal of Intergenerational Relationships, 7(2-3), 159-176. https://doi. org/10.1080/15350770902851197.

Dolbin-MacNab, M. L., Smith, G. C., \& Hayslip, B. (2020). Reunification in custodial grandfamilies. Family Relations. https://doi. org/10.1111/fare.12487.

Doley, R., Bell, R., Watt, B., \& Simpson, H. (2015). Grandparents raising grandchildren: Investigating factors associated with distress among custodial grandparent. Journal of Family Studies, 21(2), 101-119. https://doi.org/10.1080/13229400.2015.1015215.

Dunifon, R., Kopko, K., Chase-Lansdale, L., \& Wakschlag, L. (2016). Multigenerational relationships in families with custodial grandparents. In M. Harrington Meyer \& Y. Abdul-Malak (Eds.), Grandparenting in the United States (pp. 133-160). New York: Baywood.

Ellis, R. R., \& Simmons, T. (2014). Coresident grandparents and their grandchildren: 2012. https://www.census.gov/content/dam/ Census/library/publications/2014/demo/p20-576.pdf.

Engstrom, M. (2008). Involving caregiving grandmothers in family interventions when mothers with substance use problems are incarcerated. Family Process, 47(3), 357-371. https://doi.org/1 0.1111/j.1545-5300.2008.00258.x.

Feder, K. A., Letourneau, E. J., \& Brook, J. (2018). Children in the opioid epidemic: Addressing the next generation's public health crisis. Pediatrics Perspectives, 143(1), e20181656. https://doi. org/10.1542/peds.2018-1656.

Ferraro, K. F., \& Shippee, T. P. (2009). Aging and cumulative inequality: How does inequality get under the skin? The Gerontologist, 49(3), 333-343. https://doi.org/10.1093/geront/gnp034.

Font, S. A. (2015). Is higher placement stability in kinship foster care by virtue or design? Child Abuse and Neglect, 42, 99-111. https ://doi.org/10.1016/j.chiabu.2015.01.003.

Funk, R. R., McDermit, M., Godley, S. H., \& Adams, L. (2003). Maltreatment issues by level of adolescent substance abuse treatment: The extent of problems at intake and relationship to early outcomes. Child Maltreatment, 8(1), 36-45. https://doi. org/10.1177/1077559502239607.

Generations United. (2018). Raising the children of the opioid epidemic: Solutions and support for grandfamilies. https://www. gu.org/app/uploads/2018/09/Grandfamilies-Report-SOGF-Updat ed.pdf.

Gibson, P. (2002). Barriers, lessons learned, and helpful hints: Grandmother caregivers talk about service utilization. Journal of Gerontological Social Work, 39(4), 55-74. https://doi.org/10.1300/ J083v39n04_05.

Goodman, C. C. (2012). Caregiving grandmothers and their grandchildren: Well-being nine years later. Children and Youth Services Review, 34(4), 648-654. https://doi.org/10.1016/j.childyouth .2011.12.009.

Goodman, C., \& Silverstein, M. (2002). Grandparents raising grandchildren: Family structure and well-being in culturally diverse families. The Gerontologist, 42(5), 676-689. https://doi. org/10.1093/geront/42.5.676.

Gordon, L. (2018). 'My daughter is a drug addict': Grandparents caring for the children of addicted parents. Kotuitui: New Zealand Journal of Social Sciences Online, 13(1), 39-54. https://doi. org/10.1080/1177083X.2017.1413664.

Haglund, K. (2000). Parenting a second time around: An ethnography of African American grandmothers parenting grandchildren due to parental cocaine abuse. Journal of Family Nursing, 6(2), 120-135. https://doi.org/10.1177/107484070000600203.

Hansen, A. C., Brown, R., Keller, P., \& Schoenberg, N. (2020). Sources of stress and strength: Contextualizing the experience of grandparents rearing grandchildren in Appalachia. Journal of Intergenerational Relationships. https://doi.org/10.1080/15350 770.2020 .1774461 .

Hayslip, B., Fruhauf, C. A., \& Dolbin-MacNab, M. L. (2017). Grandparents raising grandchildren: What have we learned over the past decade? The Gerontologist, 59(3), e152-e163. https://doi. org/10.1093/geront/gnx106.

Hayslip, B., \& Glover, R. (2008). Traditional grandparents' views of their caregiving peers' parenting skills: Complimentary or critical? In B. Hayslip \& P. Kaminiski (Eds.), Parenting the custodial grandchild: Implications for clinical practice (pp. 149-164). New York: Springer.

Hayslip, B., Glover, R. J., Harris, B. E., Miltenberger, P. B., Baird, A., \& Kaminski, P. L. (2009). Perceptions of custodial grandparents among young adults. Journal of Intergenerational Relationships, 7(2-3), 209-224. https://doi.org/10.1080/15350770902851163.

Hayslip, B., Shore, R. J., Henderson, C. E., \& Lambert, P. L. (1998). Custodial grandparenting and the impact of grandchildren with problems on role satisfaction and role meaning. The Journals of Gerontology, Series B: Psychological Sciences and Social Sciences, 53(3), 164-173. https://doi.org/10.1093/geron b/53B.3.S164.

Hayslip, B., \& Smith, G. C. (Eds.). (2013). Resilient grandparent caregivers: A strengths-based perspective. New York: Routledge.

Honein, M. A., Boyle, C., \& Redfield, R. R. (2019). Public health surveillance of prenatal opioid exposure in mothers and infants. Pediatrics, 143(3), e20183801. https://doi.org/10.1542/ peds.2018-3801.

Hughes, M. E., Waite, L. J., LaPierre, T. A., \& Luo, Y. (2007). All in the family: The impact of caring for grandchildren on grandparents' health. The Journals of Gerontology, Series B: Psychological Sciences and Social Sciences, 62(2), 108-119. https://doi. org/10.1093/geronb/62.2.s108.

Jones, G. H., Bruera, E., Abdi, S., \& Kantarjian, H. M. (2018). The opioid epidemic in the United States-Overview, origins, and potential solutions. Cancer, 124(22), 4279-4286. https://doi. org/10.1002/cncr.31713. 
Kelley, S. J., Whitley, D. M., \& Campos, P. E. (2011). Behavior problems in children raised by grandmothers: The role of caregiver distress, family resources, and the home environment. Children and Youth Services Review, 33(11), 2138-2145. https://doi. org/10.1016/j.childyouth.2011.06.021.

Kelley, S. J., Whitley, D. M., \& Campos, P. E. (2013). Psychological distress in African American grandmothers raising grandchildren: The contribution of child behavior problems, physical health, and family resources. Research in Nursing and Health, 36(4), 373-385. https://doi.org/10.1002/nur.21542.

Kimberlin, S. E., Anthony, E. K., \& Austin, M. J. (2009). Re-entering foster care: Trends, evidence, and implications. Children and Youth Services Review, 31(4), 471-481. https://doi.org/10.1016/j. childyouth.2008.10.003.

Kocherlakota, P. (2014). Neonatal abstinence syndrome. Pediatrics, 134(2), 547-561. https://doi.org/10.1542/peds.2013-3524.

Kroll, B. (2007). A family affair? Kinship care and parental substance misuse: Some dilemmas explored. Child and Family Social Work, 21(1), 84-93. https://doi.org/10.1111/j.1365-2206.2006.00448.x.

Lander, L., Howsare, H., \& Byrne, M. (2013). The impact of substance use disorders on families and children: From theory to practice. Social Work in Public Health, 28(3-4), 194-205. https://doi. org/10.1080/19371918.2013.759005.

Landry-Meyer, L., \& Newman, B. M. (2004). An exploration of the grandparent caregiver role. Journal of Family Issues, 25(8), 1005-1025. https://doi.org/10.1177/0192513X04265955.

Lange, B., \& Greif, S. (2011). An emic view of caring for self: Grandmothers who care for children of mothers with substance use disorders. Contemporary Nurse, 41(1), 15-26. https://doi. org/10.5172/conu.2011.40.1.15.

Livingston, G., \& Parker, K. (2010). Since the start of the great recession, more children raised by grandparents. http://www.pewso cialtrends.org/2010/09/09/since-the-start-of-the-great-recessionmore-children-raised-by-grandparents/.

McGinty, E. E., Barry, C. L., Stone, E. M., Niederdeppe, J., KennedyHendricks, A., Linden, S., \& Sherman, S. G. (2018). Public support for safe consumption sites and syringe services programs to combat the opioid epidemic. Preventive Medicine, 111, 73-77. https://doi.org/10.1016/j.ypmed.2018.02.026.

Mignon, S. I., \& Holmes, W. M. (2013). Substance abuse and mental health issues with Native American grandparenting families. Journal of Ethnicity in Substance Abuse, 12(3), 210-227. https ://doi.org/10.1080/15332640.2013.798751.

Mihalec-Adkins, B. P., Coppola, E., Hines, D., Verbiest, S., \& Wadsworth, S. M. (2020). Juggling child protection and the opioid epidemic: Lessons from family impact seminars. National Council on Family Relations Policy Brief, 5(2), 1-8.

Minkler, M., \& Fuller-Thomson, E. (1999). The health of grandparents raising grandchildren: Results of a national study. American Journal of Public Health, 89(9), 1384-1389. https://doi. org/10.2105/ajph.89.9.1384.

Minkler, M., Fuller-Thomson, E., Miller, D., \& Driver, D. (1997). Depression in grandparents raising grandchildren: Results of a national longitudinal study. Archives of Family Medicine, 6(5), 445-452. https://doi.org/10.1001/archfami.6.5.445.

Minkler, M., \& Roe, K. M. (1993). Grandmothers as caregivers: Raising children of the crack cocaine epidemic. Thousand Oaks, CA: Sage.

Minkler, M., Roe, K. M., \& Price, M. (1992). The physical and emotional health of grandmothers raising grandchildren of the crack cocaine epidemic. The Gerontologist, 32(6), 752-761. https:// doi.org/10.1093/geront/32.6.752.

Minkler, M., Roe, K. M., \& Robertson-Beckley, R. J. (1994). Raising grandchildren from crack-cocaine households: Effects on family and friendship ties of African-American women.
American Journal of Orthopsychiatry, 61(1), 20-29. https://doi. org/10.1037/h0079493.

Minuchin, P. (1985). Families and individual development: Provocation from the field of family therapy. Child Development, 56(2), 289-302.

Mirick, R. G., \& Steenrod, S. A. (2016). Opioid use disorder, attachment, and parenting: Key concerns for practitioners. Child and Adolescent Social Work Journal, 33(6), 547-557. https://doi. org/10.1007/s10560-016-0449-1.

Moody, L. N., Satterwhite, E., \& Bickel, W. K. (2017). Substance use in rural Central Appalachia: Current status and treatment considerations. Journal of Rural Mental Health, 41(2), 123-135. https ://doi.org/10.1037/rmh0000064.

Musil, C. M., Gordon, N. L., Warner, C. B., Zauszniewski, J. A., Standing, T., \& Wykle, M. (2010). Grandmothers and caregiving to grandchildren: Continuity, change, and outcomes over 24 months. The Gerontologist, 51(1), 86-100. https://doi. org/10.1093/geront/gnq061.

Musil, C. M., Warner, C., Zauszniewski, J., Wykle, M., \& Standing, T. (2009). Grandmother caregiving, family stress and strain and depressive symptoms. Western Journal of Nursing Research, 31(3), 389-408. https://doi.org/10.1177/0193945908328262.

National Institute on Drug Abuse. (2020). Drugs, brains, and behavior: The science of addiction. https://www.drugabuse.gov/publicatio ns/drugs-brains-behavior-science-addiction/preface.

O'Leary, M., \& Butler, S. (2015). Caring for grandchildren in kinship care: What difficulties face Irish grandparents with drug-dependent children? Journal of Social Work Practice in the Addictions, 15(4), 352-372. https://doi.org/10.1080/1533256X.2015.10909 99.

Om, A. (2018). The opioid crisis in black and white: The role of race in our nation's recent drug epidemic. Journal of Public Health, 40(4), e614-e615. https://doi.org/10.1093/pubmed/fdy103.

Patrick, S. W., \& Schiff, D. M. (2017). A public health response to opioid use in pregnancy. Pediatrics, 139(3), e20164070. https:// doi.org/10.1542/peds.2016-4070.

Pilkauskas, N. V., \& Dunifon, R. E. (2016). Understanding grandfamilies: Characteristics, nonresident parents, and children. Journal of Marriage and Family, 78(3), 623-633. https://doi.org/10.1111/ jomf.12291.

Radel, L., Baldwin, M., Crouse, G., Ghertner, R., \& Waters, N. (2018). Substance use, the opioid epidemic, and the child welfare system: Key findings from a mixed methods study. https://aspe.hhs. gov/system/files/pdf/258836/SubstanceUseChildWelfareOvervi ew.pdf.

Rigg, K. K., Monnat, S. M., \& Chavez, M. N. (2018). Opioid-related mortality in rural America: Geographic heterogeneity and intervention strategies. International Journal of Drug Policy, 57, 119-129. https://doi.org/10.1016/j.drugpo.2018.04.011.

Roe, K. M., Minkler, M., \& Barnwell, R. (1994). The assumption of caregiving: Grandmothers raising the children of the crack cocaine epidemic. Qualitative Health Research, 4(3), 281-303. https://doi.org/10.1177/104973239400400303.

Roe, K. M., Minkler, M., Saunders, F., \& Thomson, G. E. (1996). Health of grandmothers raising children of the crack cocaine epidemic. Medical Care, 34(11), 1072-1084. https://www.jstor .org/stable/3766562.

SAMHSA. (2014). SAMHSA's concept of trauma and guidance for a trauma-informed approach. https://ncsacw.samhsa.gov/userfiles/ files/SAMHSA_Trauma.pdf.

SAMHSA. (2019). Key substance use and mental health indicators in the United States: Results from the 2018 National Survey on Drug Use and Health. https://www.samhsa.gov/data/sites/defau 1t/files/cbhsq-reports/NSDUHNationalFindingsReport2018/ NSDUHNationalFindingsReport2018.pdf. 
Seay, K., \& Kohl, P. L. (2015). Caregiver substance abuse and children's exposure to violence in a nationally representative child welfare sample. Journal of Social Work Practice in the Addictions, 13(1), 70-90. https://doi.org/10.1080/15332 56X.2013.756335.

Sepulveda, K., \& Williams, S. C. (2019). One in three children entered foster care in 2017 because of parental drug abuse. https://www. childtrends.org/one-in-three-children-entered-foster-care-in-fy2017-because-of-parental-drug-abuse.

Shanahan, L., Hill, S. N., Gaydosh, L. M., Steinhoff, A., Costello, E. J., Dodge, K. A., et al. (2019). Does despair really kill? A roadmap for an evidence-based answer. American Journal of Public Health, 109(6), 854-858. https://doi.org/10.2105/ AJPH.2019.305016.

Sheridan, K. (2014). A systematic review of the literature regarding family context and mental health of children from rural methamphetamine-involved families: Implications for rural child welfare practice. Journal of Public Child Welfare, 8(5), 514-538. https ://doi.org/10.1080/15548732.2014.948584.

Smith, G. C., Hayslip, B., \& Webster, B. A. (2019a). Psychological difficulties among custodial grandchildren. Children and Youth Services Review, 104, 104390. https://doi.org/10.1016/j.child youth.2019.104390.

Smith, G. C., Infurna, F., Webster, B. A., Dolbin-MacNab, M. L., Crowley, M., \& Musil, C. M. (2019, November 14). Adverse childhood experiences reported by custodial grandmothers and their adolescent grandchildren [Poster]. Austin, TX: Gerontological Society of America.

Smith, G. C., \& Palmieri, P. A. (2007). Risk of psychological difficulties among children raised by custodial grandparents. Psychiatric Services, 58(10), 1303-1310. https://doi.org/10.1176/appi. ps.58.10.1303.

Smith, V. C., \& Wilson, C. R. (2016). Families affected by parental substance abuse. Pediatrics, 138(2), e21061575. https://doi. org/10.1542/peds.2016-1575.

Sprang, G., Choi, M., Eslinger, J. G., \& Whitt-Woosley, A. L. (2015). The pathway to grandparenting stress: Trauma, relational conflict, and emotional well-being. Aging and Mental Health, 19(4), 315-324. https://doi.org/10.1080/13607863.2014.938606.

Stumbo, S. P., Yarborough, B. H., Janoff, S. L., Yarborough, M. T., McCarty, D., \& Green, C. A. (2016). A qualitative analysis of family involvement in prescribed opioid medication monitoring among individuals who have experienced opioid overdoses. Substance Abuse, 37(1), 96-103. https://doi.org/10.1080/08897 077.2015.1124479.

Supporting Grandparents Raising Grandchildren Act of 2018, Pub. L. No. 115-196, 132 Stat. 1511 (2018).

Taylor, M. F., Coall, D., Marquis, R., \& Batten, R. (2016). Drug addiction is a scourge on the earth and my grandchildren are its victims: The tough love and resilient growth exhibited by grandparents raising the children of drug-dependent mothers. International Journal of Mental Health and Addiction, 14(6), 937-951. https://doi.org/10.1007/s11469-016-9645-7.

Taylor, M. F., Marquis, R., Coal, D., \& Wilkinson, C. (2017). Substance misuse-related parental child maltreatment: Intergenerational implications for grandparents, parents, and grandchildren relationships. Journal of Drug Issues, 47(2), 241-260. https:// doi.org/10.1177/0022042616683670.
Templeton, L. (2012). Dilemmas facing grandparents with grandchildren affected by parental substance misuse. Drugs: Education, Prevention, and Policy, 19(1), 11-18. https://doi. org/10.3109/09687637.2011.608391.

United States Census Bureau. (2020a). Grandparents. https://data. census.gov/cedsci/table?q=S1002\&tid=ACSST5Y2019.S1002.

United States Census Bureau. (2020b). Grandparents living with own grandchildren under 18 years by responsibility for own grandchildren by length of time responsible for own grandchildren for the population 30 years and over. https://data.census.gov/cedsci/ table?q=ACSDT1Y2019.B10050\&tid=ACSDT1Y2019.B1005 $0 \&$ hidePreview $=$ true.

United States Department of Health and Human Services. (2017, October 26). HHS Acting Secretary declares public health emergency to address national opioid crisis. https://www.hhs.gov/about /news/2017/10/26/hhs-acting-secretary-declares-public-healt h-emergency-address-national-opioid-crisis.html.

United State Senate Special Committee on Aging. (2017, March 21). Grandparents to the rescue: Raising grandchildren in the opioid crisis and beyond. https://aging.senate.gov/hearings/grand parents-to-the-rescue-raising-grandchildren-in-the-opioid-crisi s-and-beyond.

Vincenzes, K. A., McMahon, B., Lange, J., \& Forziat-Pytel, K. (2019). Systemic issues in the opioid epidemic: Supporting the individual, family, and community. International Journal of Mental Health and Addiction, 17(5), 1214-1228. https://doi. org/10.1007/s11469-018-0041-3.

Whitley, D. M., \& Fuller-Thomson, E. (2017). African-American solo grandparents raising grandchildren: A representative profile of their health status. Journal of Community Health, 42(2), 312323. https://doi.org/10.1007/s10900-016-0257-8.

Williams, S. C., \& Sepulveda, K. (2019). The share of children in foster care living with relatives is growing. https://www.child trends.org/the-share-of-children-in-foster-care-living-with-relat ives-is-growing.

Wilson, N., Kariisa, M., Seth, P., Smith, H., \& Davis, N. L. (2020). Drug and opioid-involved overdose deaths-United States, 2017-2018. Morbidity and Mortality Weekly Report, 69(11), 290-297. https://doi.org/10.15585/mmwr.mm6911a4.

Wu, Q., White, K. R., \& Coleman, K. L. (2015). Effects of kinship care on behavioral problems by child age: A propensity score analysis. Children and Youth Services Review, 57, 1-8. https:// doi.org/10.1016/j.childyouth.2015.07.020.

Xu, Y., \& Bright, C. L. (2018). Children's mental health and its predictors in kinship and non-kinship foster care: A systematic review. Children and Youth Services Review, 89, 243-262. https://doi. org/10.1016/j.childyouth.2018.05.001.

Ziol-Guest, K. M., \& Dunifon, R. E. (2014). Complex living arrangements and child health: Examining family structure linkages with children's health outcomes. Family Relations, 63(3), 424-437. https://doi.org/10.1111/fare.12071.

Publisher's Note Springer Nature remains neutral with regard to jurisdictional claims in published maps and institutional affiliations. 